Est Ag 46 (2011) 291-311

\title{
La OALA en sus cuarenta años de Historia
}

\author{
P. JOAQUÍN GARCÍA, OSA*
}

RESUMEN: La década del 70 al 80 fue un momento de efervescencias fruto del Vaticano II al interior de la Iglesia. La Orden de San Agustín no podía estar ajena a estos cambios, sobre todo, después del Capítulo General Intermedio del año 1968, celebrado en Villanova. La primera reunión de lo que habría de ser en el futuro la Organización de Agustinos en América Latina (OALA) se celebraría en Quito (Ecuador) al año siguiente, en abril de 1969. Sería el comienzo de un largo proceso que culminaría con la reunión de Chile de este acontecimiento agustiniano. Fuerzas diferentes, progresistas y conservadores, han animado este proyecto durante estas cuatro décadas, que al autor describe minuciosamente. Concluye con una serie de observaciones y recomendaciones.

PALABRAS CLAVE: renovación, vida religiosa, América Latina, Agustinos.

ABSTRACT: The decade from 1970 to 1980 was a period of effervescence within the Church, a direct consequence of Vatican II. Also the Order of San Augustine was not alien to these changes, and especially after the Intermediate General Chapter of the year 1968, celebrated in Villanova. The first meeting of the future Organization of the Augustinians of Latin America (OALA) would be celebrated in Quito (Ecuador) in the following year, in April 1969. This would be the beginning of a long process of the Augustinian project that would culminate with the meeting of Chile. Various forces, progressive and conservative, have encouraged it during these four decades, which the author describes in great detail. He concludes with a series of observations and recommendations.

*Vicariato Regional de Iquitos e-mail: joaqgarcia@gmail.com 
KEY WORDS: renewal, religious life, Latin America, Augustinians.

Dentro de lo que cabe, la década de 1970 a 1980, encerró una tal ebullición de acontecimientos, rupturas, proyectos nuevos y utopías agotadas, avances y desalientos, que es muy difícil encerrar su significado en una síntesis más o menos coherente, e intentar una evaluación del acontecer en el mundo y, más, en América Latina. O, al menos, hacer un sincero "feed-back" a quienes ha tocado sufrir y gozar su apasionante aventura. En contra de lo que habían vaticinado los observadores del movimiento conciliar de que se había llegado ya demasiado tarde para subirse al tren de la historia secular del siglo $X X$, la Iglesia en América Latina insurgió como fuerza delantera no solamente en el movimiento de transformación rápida de sí misma, sino también empujando fervorosamente la marcha de los pobres del Continente, en los que encontró una fuente de conversión y energía. Sus martirologios están llenos de nombres inéditos y sus liturgias vibraron en la sangre derramada, y aumentó el número de los que se incorporaron sin miedo a la caravana de quienes andaban buscando a Jesús en el andar de los pueblos oprimidos.

La Orden de San Agustín no podía sustraerse a este clima. Y, aunque tímidamente, se puso a caminar al tiempo en que los aires de Medellín recorrían de norte a sur el cielo latinoamericano. Apenas medio año más tarde de haberse firmado el último documento de la II Conferencia General del Episcopado Latinoamericano (septiembre de 1968), el Superior General de la Orden, recogiendo una aspiración que fue tomando cuerpo en el Capítulo Extraordinario de Villanova, convocaba a una reunión de los agustinos dispersos por más de diez países ${ }^{1}$ con la intención de compartir experiencias y organizarse superando el estilo de archipiélago provincialista de vieja tradición ${ }^{2}$. Quizá el proyecto agustiniano no estuviese en plena sintonía con la marcha general de la Iglesia, mas no era casualidad que se intentase avanzar en una línea de renovación tal como se intuía que los tiempos iban exigiendo.

\footnotetext{
${ }^{1}$ Circular del Rvmo. P. General a todos los Superiores Mayores de América del Sur, de 13 de febrero de 1969, Reg. 284. Arch. Coord. Oala, C-1.

2 "Ut autem iter nostrum maiores fructus, uti speramos. afferat. volumus ut nobis praesentibus omnes Superiores maiores nationum, quae unione sic dicta CLAR comprehenduntuir simul conveniant ad problemata communia vitae religiosae et apostolatus communi consilio consideranda et oportunas solutiones suggerendas: praesertim vero ad ea in praxim deducenda quae novae Constitutiones in n. 263 praecipiunt" (Ibid.).
} 
Entiendo que hay que asumir las contradicciones habidas entre el lenguaje o discurso doctrinal y la praxis histórica o quehacer concreto.

\section{La OALA en sus orígenes}

Cuando los modelos desarrollistas habían contagiado a nuestras repúblicas crecieron también los movimientos de integración regional y sub-regional (OEA, ALALC, etc.). La Iglesia no se vio ajena a este influjo que por el año 1955 cristalizó en Río Janeiro en la creación del Consejo Episcopal Latinoamericano (CELAM), y, poco más tarde (1959), en la Confederación Latinoamericana de Religiosos (CLAR), y otras formas de organización intra-eclesial. Inmediatamente después se celebró el Concilio. Durante él los Obispos de Latinoamérica se reunieron asiduamente por las tardes para estudiar las nuevas corrientes de la teología y plantearse las exigencias de una adaptación del espíritu conciliar a las condiciones especiales de nuestros pueblos $^{3}$.

El largo Capítulo constitucional reunido en Saint Mary's Hall de la Universidad de Villanova, dejó tiempo para que algunos delegados del Hemisferio, a tono con los tiempos, estudiasen la posibilidad de una interrelación entre todas las circunscripciones ${ }^{4}$. Es posible que a esas alturas los pasillos se mostrasen preocupados por el fraccionamiento de la Orden, la desvinculación entre los distintos grupos regionales dependientes de sus centros provinciales, los crecientes conflictos entre religiosos nacionales y extranjeros en la situación jurídica de las Provincias de régimen suspendido necesitadas de personal, además de la urgente necesidad de superar una vieja rémora de las comunidades que no parecían en general interesarse por el viraje de la Iglesia ${ }^{5}$. Lo cierto es que la asamblea capitular se hizo eco de este clamor y le dio salida constitucional, consagrando en el número 263 la figura jurídica de las Confederaciones ${ }^{6}$.

No se hicieron esperar mucho tiempo los contactos entre la Curia y el P. Guillermo Saelman, por entonces Viceprovincial de Bolivia, a quien se

\footnotetext{
${ }^{3}$ Este aspecto histórico puede verse más ampliamente desarrollado en MARINS, José y equipo. Praxis de los Padres de América Latina. Los documentos de las Conferencias Episcopales de Medellín a Puebla 1968-1978, pág. 17 ss. Bogotá, 1978. Edic. Paulinas.

${ }^{4}$ Informe del Coordinador a.i., P. Pedro López, a la II Asamblea del Consejo de la OALA. Arch. Coord. Oala, C-3.

${ }^{5}$ Carta del P. Guillermo Saelman, Secretario General de la CLAR, P. Luis Patino, del día 30 de junio de 1969. Arch. Cood. Oala, C-1. Los testimonios epistolares de distintos puntos son insistentes en este mismo sentido. Hay una conciencia generalizada de rezago.

${ }^{6}$ Constituciones de los hermanos de la Orden de San Agustín. N. 263. Madrid, 1973.
} 
consideraba como destacado portavoz de estas inquietudes. El P. Salustiano Miguélez, Asistente de la II Asistencia, y el P. Saelman cruzaban en los primeros días del año 1969 abundante correspondencia que desembocó en la convocatoria, por parte del Rvdmo. P. Agustín Trapé, a todos los Superiores Mayores de América Latina a una reunión conjunta en alguna ciudad que se dejaba por determinar?

Desde el primer momento Saelman planteó para la reunión tres ejes fundamentales: 1) estudio de las nuevas Constituciones para adaptarlas a las condiciones originales de la Orden en América Latina;2) estrechamiento de los vínculos con el CELAM, la CLAR y las Conferencias Episcopales; 3) organización de una federación que canalizase en forma permanente la coordinación entre todas las agrupaciones agustinianas ${ }^{8}$. Una carta del citado Asistente sugiere, por indicación del General, añadir el estudio de la problemática vocacional y la realización de trabajos mancomunados por parte de los diversos grupos 9 .

No es difícil advertir desde el comienzo las diferencias de percepción en la manera de proyectar la federación. Por una parte se acentúa la preocupación por entrar de lleno en los nuevos aires pastorales que recorrían la geografía de Iberoamérica, y, por otra, se visualiza, más bien, una organización agustiniana con funciones de refuerzo, ayuda mutua e intensificación de la vida agustiniana en el ámbito de la Orden. Ambas posiciones se habrán de mantener vivas a través de todas las incidencias y años de la OALA. En aquel preciso momento se fueron polarizando las tendencias, desde quienes deseaban una revisión a fondo de nuestras obras, especialmente las educativas, hasta quienes preconizaban atormentados la fidelidad al Sumo Pontífice, el freno a las defecciones y otros items doctrinales característicos del terror a la crisis que por aquel entonces ya azotaba al Pueblo de Dios ${ }^{10}$. Los Superiores Mayores eran el reflejo de un agitado mundo de turbulencias que, por desgracia, no se habían resuelto. En muchos casos, no con criterios

\footnotetext{
${ }^{7}$ Cfr. Circular P. General, ut supra. Desde el 15 de enero en que el P. Salustiano Miguélez escribe para un primer contacto al P. Saelman hasta la realización de la primera reunión en Quito hay un febril intercambio de correspondencia entre Roma y La Paz; La Paz y todos los demás países de la región. El P. Manuel Soto, Asistente General para las Provincias de América Latina, no se da por informado hasta más tarde (Carta del 12-11-1969).

${ }^{8}$ Carta del P. Saelman al P. Salustiano Miguélez, del día 21 de enero de 1969. Aren. Coord. Oala, C-1.

${ }^{9}$ Carta del P. Salustiano Miguélez al P. Saelman, del 2 de febrero de 1969. C-1.

${ }^{10}$ Los archivos de la Coordinación recogen estas inquietudes que van de uno a otro extremo del movimiento pendular. Por razones obvias nos eximimos de traer citas.
} 
sanos y abiertos, sino con una definida posición integrista que tantos estragos dejó detrás de sí $^{11}$.

Por fin, 18 superiores regionales, representando aproximadamente a 800 religiosos, se reunieron en Quito del 20 al 25 de abril de 1969, bajo la Presidencia del P. General ${ }^{12}$. La orientación predominante de los fundadores queda plasmada en las actas y documento final, y no requieren mayor comentario. Se había constituido el organismo soñado, que se esperaba sirviese de instrumento útil para el afianzamiento e impulso de la Orden que desde el arribo de los primeros agustinos en 1533 a las playas de Veracruz, había mantenido una ininterrumpida trayectoria misionera. Nacía la ORGANIZACIÓN DE LOS AGUSTINOS DE LATINOAMÉRICA (OALA). Se elaboraron los primeros estatutos reducidos a lo más simple y funcional, habida cuenta de que las mentalidades no admitían un espacio de acción demasiado amplio. Un mes más tarde exactamente el Consejo General aprobaba y confirmaba los estatutos de la nueva entidad y la elección tanto del Presidente como del Vicepresidente, padres Saelman y López ${ }^{13}$. No eran muchas las dificultades con que se había topado hasta el momento. Mas no por eso la reciente criatura salía a la luz libre de interrogantes y de inciertos presagios.

Los archivos de la OALA contienen una intensísima actividad epistolar por parte de Saelman: escribe, recibe sugerencias, aprovecha ocasiones mil para establecer contactos directos con las comunidades de cada país y conocer de cerca la mentalidad de cada una de ellas, prestando atención a la generación más joven ${ }^{14}$.

En octubre de ese mismo año salió, a costa de entusiasmo y trabajo personal, el número primero del Boletín de la OALA, cargado de llamadas a adoptar una actitud positiva y colaboradora ante las nuevas tareas emprendidas ${ }^{15}$.

${ }^{11}$ Estos años constituyen la prueba más dramática para muchas circunscripciones. Grupos enteros de religiosos, después de haber pasado por centros de formación superior en lo pastoral, al encontrarse sin espacio optaron casi masivamente por abandonar la Orden. Ha transcurrido tiempo suficiente como para que se haga un análisis sereno de este fenómeno, cuyas consecuencias se sienten ahora.

${ }^{12}$ ACTA OSA, XIV (1969) 115-125.

${ }^{13}$ Carta del P. General al P. Saelman. del 28 de mayo de 1969. Reg. 284.

${ }^{14}$ En este período realiza el Coordinador varios viajes y difunde dos circulares además de contestar a numerosas cartas. Más adelante el P. Hammerlinck seguirá en un ritmo similar.

${ }^{15}$ BOLETÍN DE LA OALA, Nº 1 , octubre de 1969. "Existe alguna base para la esperanza de que la OALA será un verdadero y auténtico servicio para nuestros cohermanos. Si llega a ser un elemento burocrático más para la Orden y la Iglesia, ¡ojalá que desaparezca pronto!", dice el Coordinador en la nota de presentación. Y añade: “ ¿No seríamos nosotros mismos los únicos llamados para mostrar que todavía tenemos algo, y mucho, que ofrecer a esta comunidad latinoamericana en el siglo XX? Un esfuerzo en esta dirección ciertamente vale la pena". 
Hasta cuatro puntos de vista, si no contrapuestos radicalmente, sí poco armonizables, concurren en la primera fase de la OALA:

1. Una corriente la entiende como medio de urgente renovación de los agustinos, que globalmente son vistos casi al margen del urgido devenir de la Iglesia y de los países del Continente.

2. Otro grupo ve en ella una posibilidad de interrelación en términos más pragmáticos: colaboración con personal, apoyo económico, intercambio de métodos, etc.

3. El Gobierno General en funciones aboga por una intensificación de la espiritualidad agustiniana, adaptación de las Constituciones y reactivación de los programas vocacionales en crisis ${ }^{16}$.

4. Finalmente no faltan quienes ven en la OALA un posible mecanismo de confederación de los Superiores Mayores para poder reprimir la ola de defecciones, desviaciones doctrinales y rompimiento de la disciplina tradicional de la Iglesia.

Acumulando los diferentes puntos de vista es lógico comprender cómo el primer encuentro de Superiores se haya propuesto metas demasiado ambiciosas, al querer abarcar tantos y tan variados problemas como se reflejan en un disperso documento con tonalidad normativa. Era el tanteo de los albores, de donde habrían de salir al paso del tiempo opciones más definidas.

Un sentimiento optimista oreaba los grupos más inquietos. Se escriben cartas de apoyo, de cuestionamiento, se ofrece colaboración. Pero siempre se deja entrever cierto grado de disconformidad con la falta de participación de las bases en la creación y puesta en marcha del nuevo ente animador ${ }^{17}$. No estaban lejos las dificultades. En agosto de 1970 Guillermo Saelman es elegido Provincial de Holanda y asume interinamente la Coordinación de la OALA el P. Pedro López, Provincial de Chile, que continúa el plan de su antecesor tratando de concertar una nueva Asamblea del Consejo para los primeros meses de 1971. Es preciso tener en cuenta que en este período se han dado cambios considerables en las autoridades regionales latinoamericanas. Se convoca, pues, formalmente la II Asamblea que se ha de celebrar en Lima ${ }^{18}$, al amparo de lo normado en los Estatutos (Art. IV, 3; VI, 1-4). Mas,

\footnotetext{
16 Vid. en general Arch. Coord. Oala. C-1. Cartas de la segunda mitad del año 69 y el 70.

17 Carta Circular del Coordinador a.i., P. Pedro López, a los Superiores Mayores.

1811 de diciembre de 1970, convocando la II Asamblea del Consejo, Arch. Coord. Oala, C-2.
} 
sea por insuficiente comunicación, sea por el celo excesivo de Roma ante la posibilidad de alguna desviación desde el movimiento latinoamericano en efervescencia, el P. Trapé desautoriza la convocatoria, instando a los miembros a no asistir, y aduciendo razones de tipo legal ${ }^{19}$. A pesar de todo, la Asamblea se celebró y a la llamada telefónica de Santa Mónica, los asambleístas contestaron con un breve documento aclaratorio y manteniéndose en su posición ${ }^{20}$. El General realizó una nueva convocatoria por su propia cuenta, mientras en Santiago de Chile se reflexionaba sobre la angustiosa problemática de Latinoamérica en un momento en que el democrático país meridional experimentaba entusiasmado la alborada de un socialismo incierto, pero que constituía una apasionante aventura para los pueblos oprimidos del Tercer Mundo.

En las elecciones resultó elegido como Coordinador el P. Edmundo Hammerlink, también Viceprovincial de Bolivia, y, como Vicecoordinador, el P. Félix Valenzuela, Superior de los Agustinos de la Provincia de El Escorial residente en Brasil y Panamá ${ }^{21}$.

Los incidentes de este proceso no tienen mucha importancia. Cualesquiera hayan sido las causas inmediatas del conflicto, saltan a la vista las grandes diferencias que, imperceptiblemente se habían notado en un principio: existe un temor de cisma por parte de Roma, en la nueva imagen de América Latina en el conspecto eclesial; se da una manera distinta de interpretar los objetivos de la OALA ${ }^{22}$; y, en fin, queda claro que las Constituciones de Villanova dejaron una grieta en el muro y había que ir ampliando en el caminar la forma jurídica a tientas con los años y los traspiés.

En semejante clima de tensiones se celebró la Asamblea de Superiores Mayores de la Orden de San Agustín en América Latina ${ }^{23}$ bajo la Presidencia del P. General y con la participación de tres Obispos agustinos, dos

${ }^{19}$ Carta del P. Secretario General de la Orden a los Superiores Mayores, del día 5 de marzo de 1971, ordenando la suspensión de esta Asamblea. Arch. Coord. Oala. C-4, 21.

${ }^{20}$ Carta de los Asambleístas al P. General, con firma hológrafa de cada uno, reafirmándose en su decisión de proseguir la Asamblea. Arch. Coord. Oala. C-3.

${ }^{21}$ Acta de la II Asamblea de la OALA. Arch. Coord. Oala, C-3.

${ }^{22}$ Basta sólo considerar los esquemas preliminares de trabajo de cada una de las dos reuniones de Santiago y Lima, para advertir los contrastes.

${ }^{23}$ Nunca quedó aclarado cual de ambas Asambleas era la jurídicamente válida y llevaba la denominación de Segunda. Hay confusión en los diversos documentos: por una parte la convocatoria de la de Lima habla de Asamblea de Superiores Mayores de la Orden de San Agustín en América, mientras exige que se realicen de nuevo las elecciones de Coordinador y Vicecoordinador; por otra, el P. Hammerlinck presenta un informe a la Asamblea de Quito bajo el ordinal de Cuarta, mientras las conclusiones la denominan Tercera. Por nuestra parte a lo largo de esta obra, para mayor operatividad consideramos II a la de Santiago y III a la de Quito, considerando a la de Lima como simplemente extraordinaria. 
Asistentes Generales, doce Superiores y otros tres representantes. Al comenzar había sido también objetada la legitimidad de la misma por parte de la totalidad de los agustinos del Vicariato de Iquitos.

Un prolongado debate permitió a las aguas recuperar su cauce. Se realizaron nuevamente las elecciones con idénticos resultados que en Santiago, se aclararon algunos puntos de fricción y se reformaron aquellos artículos de los Estatutos por cuya mala interpretación había sucedido tan desigual escaramuza ${ }^{24}$. Se abre así una etapa de crecimiento y maduración de la OALA que entre la III Asamblea (Quito, 1973) y la IV (México, 1975) va a alcanzar su máximo apogeo ${ }^{25}$.

\section{Una OALA en diversos momentos}

La OALA fue fluctuando según la correlación de fuerzas que se daban en su interior, sea por factores de influencia eclesial (caso de Puebla) o por las diversas tendencias predominantes entre los superiores en diversas etapas $y$ de quienes había dependido la toma de decisiones y la orientación más oficial. Es cierto que se han celebrado muchos encuentros especializados en diversas áreas pastorales, pero siempre al margen de lo que podríamos llamar el eje decisorio. Tanto es así que muchos religiosos de base llegaron a creer que la OALA no involucraba a todos los agustinos latinoamericanos, sino solamente a los superiores. En este sentido cabe mucha responsabilidad a quienes participando del Consejo no han informado oportunamente. En la correspondencia que llega a la Coordinación se lee con frecuencia esta queja.

\section{Momento de iniciación}

Analizando con cierto reposo crítico el discurso interno de la OALA, revelado a través de los primeros documentos, descubrimos rasgos que denotan o incertidumbre o, por lo menos, un abanico abierto cargado de problemas y luces donde es muy difícil elegir entre tantas alternativas. Veamos algunos:

\footnotetext{
${ }^{24}$ Se modificaron los numerales IV 3 y Vl-3 de los Estatutos, que se refieren a las reuniones Anuales del Consejo y a la necesidad de informar al P. General de las convocatorias. Cfr. Arch. Coord. Oala, Actas de Lima, C-3.

${ }^{25}$ Para una visión del proceso en su conjunto ofrecemos una relación de las Asambleas del Consejo celebradas desde el principio hasta nuestros días como figura en la página web de OALA.
} 
- Insistencia en la espiritualidad agustiniana y "la vida interior de cada religioso como fuente de toda inspiración de nuestro testimonio religioso y nuestro apostolado" 26 .

- Asignación a la OALA de un rol unificador y animador en relación con la vida agustiniana y el desarrollo (expansión) de la Orden en el Continente.

- Nuestras comunidades en cuanto tales, "dentro de las orientaciones del espíritu religioso y de la Orden deben estar al servicio de la iglesia en América Latina"27. Y se -asegura que la "doctrina de San Agustín y de la espiritualidad de la Orden... son fuente segura para la solución de los problemas actuales de la Iglesia en nuestro Continente. Somos nosotros llamados especialmente a aportar esa luz"28.

- Se reconocen los méritos de las obras vigentes (educativas en particular) y su validez, aunque necesitadas de una profunda evaluación.

Es posible que no advirtamos grandes diferencias en el lenguaje de cada uno de los documentos. La distinción la marca el enfoque de los problemas, las soluciones que se aportan y los métodos de análisis empleados.

\section{Primer momento Latinoamericano}

La II Asamblea del Consejo de la OALA supone una decidida vocación latinoamericana en el sentido más hondo de la expresión. A partir de una teología de la Iglesia se orientan puntos como:

- La absoluta necesidad de compromiso pastoral directo. No se puede cambiar mientras el medio con que estás en contacto no lo requiera.

- Cambio radical de mentalidad en nuestras comunidades y superación de las tensiones que viven por razón de los conflictos generacionales e ideológicos.

\footnotetext{
${ }^{26}$ I Asamblea, cap. II 1.

${ }^{27}$ Ibid., cap. V, 1.

28 Ibid., cap. V. recomendaciones.
} 
- La integración de las comunidades en los esquemas de la pastoral de conjunto, priorizando en consecuencia las tareas y revisándolas en su totalidad.

- Replanteamiento del sistema educativo de nuestros colegios: mayor participación en la gestión a los laicos; orientación según el espíritu liberador de Medellín para impulsar el cambio social en los países oprimidos; aproximación al mundo de los pobres.

\section{Momento agustiniano}

Ya vimos que los problemas surgidos de la diversa interpretación dada a los términos de la convocatoria entrañaban cuestiones de carácter ideológico. En la práctica subsistían los dos polos que remarcaban acentos diversos. La Asamblea de Lima pretende desde las primeras formulaciones de su programa poner en el primer plano de la pantalla temas como la espiritualidad agustiniana, vocaciones, defecciones, apostolado, misiones, vinculación y ayuda mutua, en el orden transcrito. Este orden no es fruto de mera casualidad, sino que encierra un método al plantear el problema de la orientación agustiniana en América Latina. Método que aún se sigue instrumentando en forma bastante generalizada tanto en la estructura de nuestras obras, como en la dinámica del trabajo pastoral. De alguna manera se retoman las tesis básicas de la creación de OALA y prevalece la corriente doctrinal sobre la situacional.

Especial valor significativo tiene el tratamiento que Lima da al problema de las defecciones por parte de quienes abandonan la vida agustiniana y que se atribuyen exclusivamente a problemas de índole personal, como el descuido y la falta de vida interior, sin acertar a ver ninguna responsabilidad en la rigidez inflexible de los gobiernos de aquellos años en muchas circunscripciones $^{29}$. Es el momento en que a muchos se les plantea en forma definitiva la pertenencia a un grupo que se coloca de espaldas a la realidad tanto de la Iglesia como de la sociedad subdesarrollada ${ }^{30}$ negación en su raíz del Evangelio del amor. Por el contrario se apreciaba una realidad falsificada a través de los barrios residenciales donde están plantados nuestros templos y escuelas.

${ }^{29}$ La totalidad del Documento de Lima es un exponente de esta posición.

${ }^{30}$ Ibid., capítulo que se titula Defecciones. 


\section{Segundo momento Latinoamericano}

Cuatro años de tanteos y vacilaciones podían considerarse suficientes para dar paso a una época de mayor madurez institucional y de clara definición de su horizonte ideológico. La III Asamblea, celebrada en Quito en abril de 1973, con su fase preparatoria, marca un hito importante. A pesar de que en el fondo subsisten las diferencias da la impresión de que va ganando terreno en las filas de los agustinos el espíritu de Medellín, aunque no sin cierta pereza. Se afirma más la certeza de que los movimientos surgidos después del Concilio no eran nubes de paso. La Iglesia ya se ha venido despojando de sus solemnes paramentos para aproximarse a la miseria y hacerla propia. OALA se enlaza con la línea de Santiago de Chile y asume sin miedo en el Mensaje una eclesiología misionera, coloca las premisas para una reinterpretación del papel de la comunidad religiosa en un contexto social de lucha de clases, y se atribuye a sí misma una triple función que disipa las imprecisiones de los años anteriores: misión crítica, misión animadora, misión coordinadora ${ }^{31}$.

A esta posición pastoral corresponderá de inmediato una nueva organización que se incorpora a los Estatutos: creación de asesorías por áreas pastorales y regiones geográficas, ampliación de participantes por derecho en las Asambleas del Consejo e incluso de elección para la Coordinación y Vice-coordinación, impulso a los programas de trabajo de cada área ${ }^{32}$. En conjunto se avanza en esta época merced a un equipo homogéneo y articulado. Por todos los puntos cardinales de la geografía agustiniana hay un aliento fresco. Encuentros de pastoral en Brasil, de educadores en Venezuela y Brasil, de Misiones en Bolivia, el Boletín se distribuye con periodicidad, la correspondencia es abundante y existe interés de intercambio de personal para tareas específicas (retiros, conferencias, etc.).

Semejante oleada de fervor y búsqueda de la nueva espiritualidad no significó, al menos de manera inmediata, un cambio de actitudes $y$ obras como lo deseaba el documento de Quito y, más tarde, el de México. Es cierto que hubo siembre un desajuste entre el ritmo del discurso ideológico y el discurso de la práctica pastoral de los agustinos latinoamericanos demasiado seguros de su tradición y de la eficacia de los esfuerzos empeñados en su

${ }^{31}$ III Asamblea. 3.2.1.

32 Se distribuyó América Latina en tres áreas geográficas y de trabajo, y se incluyeron tres asesores responsables de cada una de ellas respectivamente. Cfr. III Asamblea, 3.2.3. 
larga historia ${ }^{33}$. Pero debemos reconocer que .el impulso de la reflexión era de por sí esperanzador.

\section{Momento crítico}

En México afloraron las viejas diferencias latentes. Algunas provincias latinoamericanas acusan a la OALA de no cumplir su objetivo fundamental de colaborar en las necesidades más apremiantes de dinero y personal que padecían ${ }^{34}$, otros se sentían autosuficientes para cubrir las demandas de promoción pastoral en el ambiente de sus respectivos países, no faltaron quienes plantean la desproporción entre los gastos económicos que remuevan los viajes y las reducidas ventajas que reportan. La organización logró superar la crisis. Pero detrás de tales desasosiegos bullía cierto descontento por la orientación que se venía dando a la OALA. Así prevalecerá en adelante una tendencia mucho más conservadora y congregacional.

Es razonable comprender cómo desde entonces disminuyó el interés por la OALA en cuanto medio de grandes posibilidades de servicio. Muchos se han tranquilizado al ver alzado el dique. Por una lenta decantación hemos llegado a una circunstancia en que prácticamente se le atribuye la misión de convocar reuniones por áreas de trabajo, en las que hermanos de diversas naciones conviven fraternalmente y comparten experiencias sin mayores compromisos. Y nada más.

A buen seguro que se ha dado con el centro de gravedad y hasta aquí alcanzaron las posibilidades de una organización confederada en una estructura marcadamente provincialista como la de la Orden agustiniana. No podíamos pedir a OALA lo que desde hace muchos años no podía siquiera conseguir el Gobierno General, que más tarde tendría de algún modo una intervención directa.

Datos sociológicos confirman esta tesis. En los últimos diez años ha disminuido alarmantemente el número de vocaciones, y es cada vez menor el número de religiosos qué llegan desde los países de origen (España, Holanda, Italia, EE.UU.). Esto determina una media edad promedia bastante superior a la de años anteriores y, por lo tanto, un equilibrio estable en las obras asumidas, en las posiciones mentales y en las actitudes de vida.

\footnotetext{
${ }^{33}$ Más bien que dejarse unas tareas tradicionales para tomar otras nuevas de conformidad con las exigencias nuevas, se han incrementado y ampliado las primeras.

${ }^{34}$ Ya en Quito los hermanos de la Provincia Ecuatoriana habían presentado a la Asamblea serias quejas sobre la ineficacia de la OALA en la solución de sus angustiosos problemas de personal.
} 
No se puede negar que el incremento del espíritu de fraternidad y la relación entre todos los hermanos de Latinoamérica haya sido un logro de la OALA, amén de la superación de prejuicios ancestrales entre nacionales y extranjeros, entre Provincia y Provincia.

\section{Una etapa de silencios}

Después de la V Asamblea del Consejo celebrada en Belo Horizonte en 1977, y la VI celebrada en Iquitos, en 1979, la OALA entra en una fase de amortiguamiento, cuyas causas no son fáciles de discernir: pérdida del entusiasmo primero, o asunción de la dirigencia de personas no suficientemente informadas de los orígenes, ocupación de personas cuyas prioridades en el trabajo eran otras o falta de participación de las bases. Tenían que transcurrir tres años para que el propio Superior General haya invitado al P. Aurelio Zárate a convocar la VII Asamblea que se celebraría en Buenos Aires en abril de 1982, precisamente cuando resonaban en Las Malvinas las trompetas de guerra. La elección a partir de las antiguas reglamentaciones recayó sobre el P. Prudencio Calzada como Presidente y el P. Joaquín García como Vicepresidente, con el encargo de hacer una revisión de las estructuras de la organización y celebrar en 1983 una Asamblea Extraordinaria en Conocoto donde se aprobaría la nueva organización. Era un paso adelante. La crisis había servido para superar un momento de oportunidades nuevas y modos de estructurar orgánicamente lo que habría de constituir el futuro de la OALA.

Una de las primeras medidas de este equipo fue la de invitar a participar en esta tarea a todos y cada uno de los agustinos del Continente, primero a través de una encuesta y, más tarde, convocando a una reunión de representantes de bases de cada una de las circunscripciones (Lima, enero de 1983) con el fin de evaluar los años de historia recorridos y presentar alternativas y propuestas. En esta ocasión se elaboró un proyecto de Estatutos que meses más adelante sería sometido a aprobación definitiva. Para ello se reunió en Conocoto (Ecuador) la VIII Asamblea del Consejo (Extraordinaria) desde el 30 de mayo al 3 de junio de 1983. En un consenso general y un espíritu unánime a favor de la unidad latinoamericana y de fe en el valor de la OALA se aprobaron los Estatutos, dejando abiertas una serie de recomendaciones para el Programa a realizarse a partir de la IX Asamblea del Consejo que habría ya de regirse por el renovado instrumento legal en San Juan de Puerto Rico del 11 al 16 de febrero de 1984. 


\section{El marco constitucional}

El Capítulo Constitucional de Villanova fue ocasión para provechosos intercambios entre los representantes latinoamericanos. Habían pasado años de insularidad para cada circunscripción, que, en la mayoría de los casos, mantenía vínculos demasiado dependientes de las provincias de origen. Los grupos de autóctonos sostenían una lucha por su autodeterminación, tanto en los casos de circunscripciones sometidas a regímenes de excepción jurídica (Viceprovincias o Provincias de Régimen Suspendido), alegando descuido en el trabajo de promoción vocacional e interés por mantener las propiedades a título de la Provincia, cuanto en las provincias asistidas bajo los auspicios directos del Superior General. En este marco tiene origen la creación de la $\mathrm{V}$ Asistencia para las provincias latinoamericanas pocos años atrás.

La coyuntura se presentaba excepcional para desencadenar un movimiento de integración que, aunque en los principios tuviese un mínimo de estructura y sin mayor influjo, podría convertirse en una fuerza de transformación y unificación, para que los hijos de Agustín tuviesen en América Latina un peso significativo.

De inmediato la sala capitular se hizo cargo de la propuesta, la hizo propia, y, sospecho que sin mayores reticencias, dio carta de ciudadanía a una nueva figura en nuestra historia jurídica: las federaciones ${ }^{35}$.

Aquella norma legal se convirtió en experimento pocos meses más tarde. El P. General convocó el primer encuentro de superiores de Latinoamérica, y desde ahí poco a poco fueron apareciendo las dificultades propias de lo que comienza a caminar. Quizá las cosas hubiesen sido de otra manera de haber precedido una mayor conciencia por parte de las bases. Un programa elaborado en la cúpula del aparato legislativo y sin reflejar ningún nivel de experiencia previa corría el riesgo de petrificarse, bien por reacción o por falta de interés ${ }^{36}$. Sin embargo, la idea fue acogida favorablemente, aunque de manera imprecisa. La Curia, como vimos antes, se inclinaba hacia el centralismo, mientras que en las circunscripciones existía una voluntad de que la OALA fuese más autónoma en su organización. De aquí surgen las primeras diferencias entre ambos polos, con distinto proyecto y mentalidad.

La inserción del Art. 263 en las nuevas Constituciones llevaba dentro de sí una limitación jurídica substancial: al considerarse las federaciones

${ }^{35}$ Constituciones de los hermanos de la Orden de San Agustín. N. 263. Madrid, 1973. Regla y constituciones de los hermanos de la Orden de San Agustín, N. 264. Madrid, 1979.

${ }^{36}$ Es muy poca la gente agustina que conoce la estructura y alcances de la Organización. 
como válidas en nuestra estructura de gobierno, obviamente imposibilitaban el acceso "pleno iure" a otros grupos de agustinos ajenos a nuestra Orden y en igualdad de circunstancias que nosotros. Muchas han sido las declaraciones que se han venido haciendo ${ }^{37}$ con la intención de que se amplíe el espectro participativo. Apenas algunas religiosas agustinas han podido asistir a reuniones sobre temas especializados, mientras que otras congregaciones no han mostrado interés alguno. Dudo que tenga futuro este esfuerzo si la fuente legal sigue siendo el artículo en cuestión pues sería necesaria su reformulación. Otras federaciones agustinianas han tenido otra dirección no acogiéndose a esta norma (Federación de Agustinos Españoles (FAE), Augustinian Pacific and Asían Conferencie (APAC).

Esto supondría una pérdida de resonancia en el ambiente agustiniano internacional. Para nosotros, procedentes entonces en más del $50 \%$ de países no latinoamericanos, el contacto con el lugar de origen era fundamental. Ya se venía jugando una baza de vida o muerte y nos encontrábamos en la misma frontera de la reflexión teológica, en el desafío a nuestra vida evangélica de un mundo de pobres, de aplastados, de injusticia. Hasta el momento, salvo el caso un poco tardío de la participación del P. Hammerlinck en la Comisión Internacional para el estudio del lugar de la Orden en el Mundo Moderno ${ }^{38}$, se desconoció otra representación de la OALA más allá de lo continental ${ }^{39}$.

Es curioso observar cómo en la obra que por aquel tiempo editaba la Curia General, donde se recogían los discursos más importantes de los Superiores Generales en los últimos 25 años, de los 17 transcritos ni uno sólo trataba sobre Latinoamérica. O lo que se ha dicho sobre la Orden en este mundo tenía entonces poca importancia para los editores, o los editores no han hallado nada de relieve que haya podido incorporarse a libro de tanto interés ${ }^{40}$.

El análisis de la experiencia del período que iba desde 1969 al 1984 se sustentaba sobre tres principios indicados por primera vez en la Asamblea

${ }^{37}$ IV Asamblea, 4.8. Es la primera vez que se sugiere invitar a otras ramas del tronco agustiniano.

${ }^{38}$ Oficio del P. General, del 9 de enero de 1974, Reg. 285. Arch. Coord. Oala, C-4, 21.

${ }^{39}$ El P. General niega autorización al P. Saelman para participar en el Congreso de Estudios de El Escorial. Según éste lo había solicitado en carta del 17 de julio de 1969. Cfr. Carta del P. Secretario, del 24 de julio de 1969. Arch. Coord. Oala, C-1.

${ }^{40}$ Libres bajo la Gracia. Espíritu y Vida de la Orden de San Agustín en los escritos de los Papas y Priores Generales (1953-1978). Curia Generalizzia Agostiniana. Roma. 1979. Contiene 17 mensajes de los Superiores Generales, además de los de los Sumos Pontífices. De ellos sólo hay un discurso pronunciado en la inauguración del Seminario de la Provincia de Michoacan (México, 26 de agosto de 1975), y un mensaje dirigido a la Orden desde Lima por el Rvdo. P. Tack, pero que no tiene una intencionalidad latinoamericana. 
de Quito (1973), y que vendrían a perfilar los objetivos y misión de la Organización: misión crítica, misión de animación, misión de coordinación. Todo un replanteamiento, en que habían confluido una parte muy considerable de las voces agustinianas de nuestros países, se estaba cristalizando. Los Estatutos asignaron al Presidente de la Asamblea del Consejo funciones representativas, en tanto que las responsabilidades ejecutivas se encargaban al Secretario General quien con cuatro Coordinadores habría de formar un equipo que anualmente definiría sus políticas concretas de trabajo en plazos trienales. Se reconocía de modo explícito que todos y cada uno de los agustinos de América Latina eran miembros de la OALA y que, en consecuencia, cada Circunscripción tenía el derecho a elegir democráticamente un Delegado a la Asamblea del Consejo con voz y voto.

Una propuesta emanada de la Asamblea de Conocoto (1983) llegaría al Capítulo General de ese mismo año pidiendo se designase un solo Asistente General para toda la América Latina. Fue aprobada y el P. Pedro López sería el primer interlocutor y partícipe de parte de Roma en un intenso trabajo que suponía, sobre todo, recuperar la confianza de todos los hermanos.

En la X Asamblea del Consejo de la OALA, celebrada en Bogotá en marzo de 1987 se añadió a la Secretaría General la Coordinación de Medios de Comunicación Social, y se definieron con mayor precisión las atribuciones del Secretario General, sobre quien recaían todas las funciones ejecutivas, y del Presidente a quien correspondía escuetamente convocar y presidir la Asamblea del Consejo (Vid. Boletín OALA, XVIII, N. 33).

En Marzo de 1990 se realizó en Méjico la XI Asamblea, presidida ya por el P. Jesús Guzmán, elegido Asistente General para América Latina en el Capítulo General celebrado en Roma (septiembre de 1989), añadiéndose en esta ocasión una nueva Coordinación a la Secretaría General, la de Justicia y Paz (Vid. Boletín OALA. XXI, N. 42-43). En febrero de 1993 tuvo lugar la XII Asamblea en Santiago de Chile (Vid. Boletín OALA, XXIV, N. 54), ocasión donde se desarrolló una aguda controversia de posiciones contrapuestas en lo referente a la orientación de la OALA. Estimo que fue una suerte de kairós que hacía que los agustinos de AL defendiésemos aquello en lo que realmente creíamos y estuviésemos dispuestos a poner las ideas al debate.

\section{El movimientos de Conocoto}

El P. General, fray Miguel Ángel Orcasitas, en base a la resolución del Capítulo General del 89 que encargaba a la Curia General pusiese especial 
atención al desarrollo de la vida de la Orden en las distintas zonas del mundo, convocó en 1991 a todos los Superiores Mayores de América Latina a un Encuentro que tendría lugar en Conocoto (Ecuador) en septiembre de 1993, y donde se trataría de aplicar a nuestra espiritualidad agustiniana y métodos apostólicos las conclusiones de la IV Asamblea General del Episcopado Latinoamericano reunida en Sto. Domingo de octubre de 1992. Para ello lanzó una encuesta a todos y cada uno de los hermanos que trabajaban en el Continente, en un universo de cerca de 600 encuestas respondidas en la casi totalidad, sobre las percepciones de la situación de la Orden en América.

Los 61 participantes se abrieron a una visión eclesial más amplia y abierta a las realidades concretas de América Latina, desde ópticas económicas, culturales, políticas y religiosas, con especial acento en el futuro de esperanza. De allí salió acuñada definitivamente la frase EL ESPÍRITU DE CONOCOTO, que en 1996 tomaría el nombre de HIPONA: CORAZÓN NUEVO.

No habría de pasar mucho tiempo para que el movimiento del Espíritu de Conocoto se vinculase a la OALA de manera natural. Tengo la vaga impresión de que la dependencia directa de la Curia General ha restado fuerza a una institución que hasta entonces era la expresión de la totalidad de los miembros y gozaba de cierta autonomía en la orientación de su praxis. Tal vez se haya debido a la urgencia de evitar tensiones al interior del conjunto de los agustinos del Continente. Ambos proyectos podrían caminar simultáneamente, sin duda. Pero la superposición parecería que la prevalencia del Espíritu de Conocoto ha restado vigencia a la fuerza activadora de la Organización como activadora de la conciencia de base en la visión pastoral agustiniana del conjunto.

A partir de la XIII Asamblea de Panamá, celebrada en febrero de 1995, las formas reglamentarias se transformaron, diversificaron las regiones, y duplicaron los años electorales. Se dio un impulso mayor a la participación de cada uno de los agustinos que trabajaban en AL. La vigencia de este gobierno ha desarrollado intensa actividad.

La siguientes asambleas se han celebrado así: XIV, en Lima el 1 de febrero del 1999 (Const. N.274); XV, el 31 de enero del 2003 en Cochabamba (Const. N. 274); Buenos Aires (Const. N.274), el 2 de febrero del 2007.

\section{Dificultades aún latentes: las relaciones en los grupos}

La historia de nuestro compromiso evangelizador con el Nuevo Mundo está salpicada de páginas gloriosas. Quizá el método tradicional de análisis 
haya sido insuficiente y nos haya llevado a elaborar relatos triunfalistas y exclusivos. Aun mirando nuestro aporte a la Evangelización de América desde una perspectiva popular es más que seguro que nuestros cuatro siglos de aporte tienen un valor incalculable. Faltan por estudiarse detenidamente los métodos catequéticos, la actitud comprometida y encarnacionista con los pueblos indios aplastados por la tiranía de los encomenderos ${ }^{41}$, y el diseño del monasterio agustino concebido como pequeña iglesia al servicio del pueblo pobre, como sucede en la arquitectura de Acolman en las cercanías de México.

Pronto surgieron las fricciones en la política interna, debido a la conformación de algo así como dos clases sociales, parapetadas en frentes irreconciliables: los metropolitanos y los criollos. Sociológicamente la Orden vive el mismo ambiente que se respira en las calles de los burgos, donde el descontento crece a medida que se agudizan las contradicciones entre España y las Colonias. Esto ayuda a explicar la amplia participación de la Iglesia en el movimiento de emancipación.

Pues bien: el trabajo que se ha venido realizando durante el siglo $\mathrm{XX}$ en favor de las provincias a punto de extinguirse, ha tenido su tinte neocolonial y de desconfianza en los valores nativos. Se han pretendido explicar los fenómenos de la decadencia de las provincias americanas por razones inmediatistas. Se esconde detrás de una actitud etnocéntrica, muy distante del auténtico espíritu evangélico. El resultado ha sido la continuación, a veces a cielo descubierto, a veces latente, de las fricciones entre los religiosos nacionales que han reclamado políticas de autonomía y los fijados a la tradición de su origen inexpugnable. Se revela de este modo la falta de una perspectiva eclesial y misionera de la comunidad, a cambio de un provincialismo sectario. Encontrándonos con el pueblo desgarrado llegaremos a un nuevo género de comprensión del sentido de la vida religiosa y agustiniana ${ }^{42}$. A la OALA le cabe desarrollar estrategias tendientes a superar estas barreras reales.

\section{Algunos comentarios al proceso de los cuarenta años}

No podríamos de ninguna manera dejar de afirmar que la OALA ha tenido una importancia decisiva en el paso de la Orden en casi una mitad de

${ }^{41}$ Vid. en este sentido en GUTIÉRREZ, David. Historia de la Orden de San Agustín. Vol. II. Los Agustinos desde el protestantismo hasta la restauración católica 1518-1648. p. 228 ss. Roma. 1997]. Una copiosa bibliografía histórica, recogida en esta obra pudiera ser la fuente para un trabajo histórico de nuevo cuño, donde se descubra el real papel evangelizador de los agustinos al margen de cualquier presunción triunfalista.

${ }^{42}$ IV Asamblea. 2. 
syglo en esta parte del mundo. El sentido de unidad articulada, los temas especializados de reflexión en cada una de las áreas de trabajo, la fuerza de las declaraciones a favor de la paz y la justicia, el cultivo de la fraternidad agustiniana entre los miembros de la Orden, el crecimiento de las vocaciones autóctonas, que se deberían al espíritu surgido de los distintos encuentros. En tiempos de globalización ha sido un avance hacia la comunión desde las complejidades. Tal vez el Espíritu de Conocoto, más definido en el Proyecto HIPONA CORAZÓN NUEVO, no hubiera tenido una significación mayor sin haber tenido como base de unidad este organismo concertador en las diversidades agustinianas. No deja ni mucho menos de haber tenido importancia.

Pero no podríamos dejar de reconocer que la institucionalidad ha dejado de tener peso e influencia en diversos aspectos que quisiera respetuosamente poner sobre la mesa.

1. Un marcado empeño en fortalecer la institucionalidad de la Orden más que abrir los ojos en perspectivas pastorales y misioneras, aunque hayan sido incluidas con un enfoque marcadamente doctrinal agustiniano en las diversas instancias. San Agustín es la raíz de nuestra interpretación. Nosotros tenemos que saber interpretarlo desde la realidad y confrontarlo con el Evangelio.

2. Esta mirada hacia sí misma, a pesar de los esfuerzos por hablar de lo diferente, interpretándolo de modo intelectual y racional, nos ha dejado fuera del avance arrollador de la historia. Acopiar vocaciones no necesariamente significa más que atención a lo cuantitativo espiritual, no descubrir nuevos caminos en el quehacer evangelizador a partir de los diferentes contextos locales para dar a la Orden de San Agustín todo el esplendor que tuvieron las primeras comunidades de vida agustiniana es en cierto modo salir de la ruta.

3. Carecemos de un buen nivel de relación con el mundo de la ciencia, falta un debate desde la situación de las comunidades indígenas, de género $\mathrm{y}$ un involucramiento en el drama de la comunidad internacional que es el Cambio Climático, que viene agostando el mundo, más allá de lo que significa la presencia de la Orden como ONG de las Naciones Unidas, donde hemos llegado tardíamente.

4. Falta una apertura a otras agrupaciones eclesiales, tal y como fuera la intención de los fundadores: continuar la reflexión sobre los grandes temas del Concilio Vaticano II, la CLAR, articulación de encuentros congregacionales y creación de redes alternativas que busquen nuevas formulaciones del desarrollo humano, etc. La OALA no tiene estas responsabilidades 
directas, pero puede ser un espacio donde se debatan los temas que más angustian al mundo, y se innove la visión de la acción evangelizadora. No por eso se han de dejar de tener en cuenta los grandes momentos de las Conferencias Episcopales de Latinoamérica. Desde Río de Janeiro hasta Aparecida serían un faro conductor que no quitase la intuición propia de los grupos de las órdenes y congregaciones a partir de las realidades concretas y locales para abrirla a nuevos espacios, conceptos y paradigmas. Todo lo que pensamos pasivamente del desarrollo desde abajo y desde adentro lo debemos debatir al interior de las distintas mesas en la organización agustiniana

5. Debiéramos haber crecido en nuestros saberes, en nuestras categorías de juicio, en nuestra capacidad de aportar a la construcción de un mundo cada vez más fraterno y más justo. El Boletín de la OALA, es un vínculo permanente, pero no es suficiente para alimentar nuestra reflexión desde la condición de los más pobres. Debiéramos avanzar nuestra reflexión a través de un órgano de alta divulgación sobre los temas de análisis que atañan a los distintos universos sociales y culturales de América Latina, donde nuestra voz tenga una entonación diversa y cada circunscripción le ponga acento a aquellos aspectos que reflexivamente surjan del análisis de la propia realidad.

\section{Algunas recomendaciones finales}

Séanme permitidas algunas observaciones que hago desde mi corazoncito de historiador cuya vocación es guardar memorias en las tierras de misión. Por otra parte dejo constancia de que durante treinta y seis años he estado al servicio de la construcción del Reino con mis hermanos los agustinos a través también de este instrumento articulador que es la OALA, donde actualmente soy miembro de la Comisión de Historia. Y lo digo con la misma pasión con que Martin Luther King hablara a la multitud poco antes de ser asesinado su "I dream...":

Sueño que, por pequeñas o recientes que sean, todas nuestras circunscripciones, aun con escasos recursos humanos y financieros, desarrollen una acción pastoral inculturada, en cualquier sociedad donde se encuentre. Lo que cada una disponga de riqueza y sabiduría, debe compartirlo en esta línea con las demás circunscripciones.

Sueño que en esta tarea se involucre a los agustinos más jóvenes, a las casas de formación, y a los distintos movimientos agustinianos que se están 
generando en la actualidad (Laicos Agustinos y cualquier otro movimiento laical vinculado a la Orden de San Agustín).

Sueño que a partir de la memoria del pasado agustiniano se genere expectativa, ilusión, para la elaboración de renovados contenidos y acciones pastorales, que no estén desvinculadas ni de la sociedad establecida ni de la iglesia local, que se abran al horizonte de un mundo en transformación.

Sueño que algún día dejemos de pensar que la cultura de nuestra identidad se realice solamente desde el pasado, por el presente hacia el futuro. Tenemos de nuestros antepasados una herencia visible e invisible, guardada en la memoria de los archivos y documentos históricos sobre el quehacer de la Orden en cada circunscripción, en espacios urbanos desde donde es posible erigir formas nuevas de recrear el futuro.

Sueño realizar un inventario de los espacios históricos en América Latina o patrimonio inmaterial (canciones, tradiciones, costumbres, plazas, jardines y calles) relacionados con nuestros antepasados.

En fin, sueño que logremos dejar diseñado un futuro de esperanza a quienes han de recibir nuestra herencia en esta región tan cargada de sufrimiento pero también de esperanza. Así la orden significará mayor variedad de colorido y seremos más diversos, pero más unidos.

Iquitos, 18 de octubre del 2009 